\title{
Chapter 5 \\ Ecological Compensation and Green \\ Development Institutional Reform \\ in the Yangtze River Economic Belt
}

\subsection{Introduction}

In 2018, China Council for International Cooperation on Environment and Development (CCICED) launched a Special Policy Study (SPS) project called Ecological Compensation and Green Development Institutional Reform in the Yangtze River Economic Belt (YREB), which aimed to solve the problem of how to construct ecological compensation mechanisms and implement green development system reform in the context of ecological protection and sustainable development. Through two years of project research, the research team has conducted in-depth studies on ecological compensation and green development system reform in the YREB and submitted specific and operable policy recommendations to promote ecological compensation and green development in the region. In 2020, the project will continue to deepen the research on reform of the YREB and green development. It will examine how to solve the lack of ecological compensation standard and green financial innovation by focusing on innovative research into natural ecological capital accounting (NECA) and an eco-financing mechanism (EFM), and their application in policy practices. It will provide scientific support for the strategic development and decision-making mechanism of YREB as well as in the Yellow River basin.

Based on the review of local NECA practices and the current situation and trends in ecological investment and financing policies, the overall goal of this project is to identify the current challenges of applying NECA and summarize the best national and international practical cases, experiences, and enlightenment that could inspire China in current and future practices. Through the design of short-, medium- and long-term policy implementation roadmaps, the project will eventually propose policy recommendations for incorporating NECA and EFM with high-quality development and high-standard protection for both YREB and Yellow River basin. 


\subsection{Status and Trends}

\subsubsection{Methodology of Ecological Capital Accounting}

Ecological capital includes natural capital as "stock" capital and ecosystem services as "flow" capital. At present, NECA is mainly reflected in the accounting of ecosystem services in order to estimate "flow" capital value. The objective of ecosystem services accounting is to assess the benefits for human welfare and sustainable socioeconomic development. These ecosystem services are subdivided internationally into provisioning, regulating, and cultural services.

Provisioning refers to the production of services like food and water. Regulating refers to the control of climate and disease and includes climate regulation, water conservation, soil conservation, flood storage, pollutant degradation, carbon sequestration, oxygen release, and pest control. Cultural services include spiritual and recreational benefits.

In 1967, Krutilla introduced existence value into the mainstream economic literature for the first time, laying a theoretical foundation for the subsequent quantitative assessment of the value of ecological capital [1]. NECA includes physical and monetary accounting, which mainly accounts for the direct use value, indirect use-value, and non-use value of ecological capital. Among them, the physical amount of ecological capital is quantified by various approaches, including statistical methods and remote sensing analysis methods, such as the CASA model, USLE model, InVEST model, etc. The monetary value can be calculated by a variety of methods, including adopted market value method, expense expenditure method, travel cost method, recovery and protection cost method, shadow price method, opportunity cost method, contingent valuation method, and other environmental-economics methods. Due to different conversion standards, the value of ecological capital is not consistently evaluated by different valuation methods. In general, the direct use value of ecological capital uses the market value method, the indirect use value uses the alternative market method, and the non-use value applies the contingent valuation method.

In practice, the value of ecosystem services can be calculated by complementary, bottom-up and top-down equivalent factor methods. The bottom-up valuation method is based on the quantity and the unit price of ecosystem services that are aggregated to estimate the total value of ecosystem services. This method originated from the article, "The Value of the World's Ecosystem Services and Natural Capital," published by Costanza et al. in Nature in 1997 [2], and applied in China by Wenhua Li [3], Zhiyun Ouyang [4, 5], and other national scholars. It is very pertinent for assessing local conditions. According to the ecological characteristics of a specific region at a certain time, the ecosystem services are summarized one by one, and the corresponding value is estimated according to the unit price of the service for that year. However, due to the different types of ecological assets, specific accounting indicators, and valuation methods, the comparability of accounting results remains uncertain. 
Due to the difficulty and uncertainty in the implementation of the bottom-up approach, some scholars have used the equivalent factor method to simplify how the value of ecosystem services is calculated using a top-down perspective. Based on the research of Costanza et al. [2], Gaodi Xie conducted several questionnaire surveys of more than 700 professionals with ecological backgrounds in China and published the Equivalent Factor Table of Value of Terrestrial Ecosystem Services in China [6]. This method estimates the value equivalent of various services provided by different types of ecosystems based on quantifiable criteria and then evaluates ecosystem services according to their regional distribution. It has the advantage of using unified methods and consistent standards. It is intuitive and easy to use with fewer data requirements and provides a comprehensive evaluation and easily compared results. However, it provides a rather macroscopic average value that cannot fully reflect the specific ecosystem characteristics of different regions.

Currently, the literature on understanding the gendered implications of ecological capital accounting is limited, but it is growing and will be factored into the overall approach recommended through this SPS.

\subsubsection{Ecological Investment and Financing Policies}

As the core of ecological protection, policies for ecological investment and financing determine how funds for ecological protection are collected and spent. They also reflect the various relationships among ecological economies. Therefore, the design of ecological investment and financing policies should not only consider the entities and channels of investment and financing but also reflect the economic, social and eco-environmental benefits they provide [7]. "Green finance" refers to financial services for project investment, financing, operating and risk management that support projects involving environmental improvement, and tackling climate change, promoting conservation and the efficient use of resources, energy conservation, clean energy, green transportation, green building, etc. [8]. The scope of projects supported by ecological investment and financing specifically in this study is smaller than that of "green finance," but the means of investment and financing are similar.

It is generally believed that, internationally, in the design of ecological investment and financing policies, considerations should be given to strengthening the government's leading role in the EFM, developing the EFM in the form of publicprivate partnerships under the guidance of the government. This approach effectively reduces the risk of private investment, improving the efficiency of ecological investment and reducing the cost of ecological investment [9-11]. Chinese scholars believe that China's current ecological investment demand and financing needs are huge; however, the government's devotion to ecological environmental protection is so far insufficient. China should draw lessons from international experience, accelerate the development of a diversified pattern on investment and financing in the field of 
ecological, environmental protection, expand investment and financing channels for ecological and environmental protection, and formulate relevant policies to ensure investment and financing channels are more feasible [12,13].

Several national and international research projects involving the quantitative analysis of ecological investment and financing policy design have been carried out. Subhrenduk [14] adopted the market value approach to calculate the value of ecological services provided by the upper stream of the river basin to the lower stream, served as references for the ecological compensation standards. The Organisation for Economic Co-operation and Development (OECD), together with the Danish Environmental Protection Agency and the Danish consulting firm COWI, applied computerized decision support tools to develop environmental financing strategies for countries in Eastern Europe, the Caucasus, and Central Asia (OECD, 2003). By building a system dynamics model for the study of the effects of multi-channel financing, using water quality changes across river basins as a criterion, Mingkai Zhang [15] simulated the effects of multi-channel funding for a watershed ecological compensation fund. He indicated that a single source of financing could not achieve the effectiveness of watershed eco-compensation, but diversified financing channels could have a better effect. Accordingly, China should accelerate the establishment of a leading platform for trading ecosystem services, similar to those for emissions trading, to attract the participation of various forms of finance.

\subsection{Progress to Date}

\subsubsection{Progress on NECA}

In 1997, Costanza et al. evaluated global ecosystem services for the first time and proposed a classification of ecosystem services that included 17 indicators. In 2001, the UN-initiated Millennium Ecosystem Assessment (MA) [34] classified ecosystem services into four functional categories: provisioning services, regulating services, cultural services, and supporting services. Since then, The Economics of Ecosystems and Biodiversity (TEEB) [35], supported by the UN Environment Programme, examined the economic valuation of ecosystems. The Final Ecosystem Goods and Services Classification System (FEGS-CS) of the United Nations Statistics Division and the National Ecosystem Services Classification System (NESCS) has developed new accounting systems based on the MA accounting framework.

Building on international accounting experience, Chinese scholars have also actively explored this issue. Zhiyun Ouyang, Gaodi Xie, Bojie Fu, and other scholars have helped to construct China's evaluation index system of ecosystem services. The former State Forestry Bureau and State Oceanic Administration have issued guidelines including the LY/T 1721-2008 [37] Specifications for Assessment of Forest Ecosystem Services in China, the GB/T 28058-2011 Technical Directives for Marine Ecological Capital Assessment, the LY/T 2006-2012 [36] Assessment Criteria of 
Desert Ecosystem Services in China, and the LY/T 2735-2016 Norm of Techniques for Valuation of Forest Resources Assets, to promote ecosystem services assessment processes covering forest, ocean, wetland, desert, etc.

Wetlands are the most complicated ecosystems from the perspective of NECA. They involve the mechanisms and processes of hydrology; the material cycle of carbon, oxygen, nitrogen, phosphorus, and other elements; biodiversity maintenance; water flow regulation; water and soil conservation; and cultural landscape. Their ecological processes, functions, and services contain a non-linear relationship with social welfare. Ecosystem services present a high degree of spatial heterogeneity and dynamism. The international experiences of ecological services focus on water resources, water conservation, and disaster mitigation based on integrated river basin management, land and water resources use, and economic policy design [16, 17] to analyze relationships between economic development and ecological services, upstream protection and downstream development, agricultural development, and land-use scenarios with associated impacts on ecosystems [18-21].

\subsubsection{Practice of PES}

The results of NECA have been studied and applied in the design of ecological compensation policies. At present, ecological compensation has been extended from a single element, such as for river basins, forests, grasslands, and wetlands, to comprehensive coverage, such as for red lines for ecological protection, key ecological functional zones (KEFZ), and national parks. The most direct purpose of ecological compensation is to protect the ecosystem in order to achieve the goal of sustainable provision of ecosystem services. Therefore, the services provided by ecosystems are an important scientific basis for the design of an ecological compensation system $[4,5]$.

As an important tool to adjust the environmental and economic behaviours of relevant stakeholders, achieve the sustainable development goal of the river basin, and effectively protect aquatic ecosystems, payment for ecosystem services (PES) in river basins has been implemented internationally for a long time. Some PES has focused on improving ecological services: the compensation standard is tied to the ecological function of water resources and costs of restoration [19, 22, 23] or the trade of ecological services based on a voluntary framework [15, 22]. This approach mainly involves the provision of ecosystem services and products in a river basin being compensated through market mechanisms or government funds. Eco-compensation and ecological restoration practices have been carried out in the Danube River basin in Europe, the Nile River basin in Africa, the Mississippi River basin in North America, the Amazon River basin in South America, and other major transnational and inter-state basins. 
China also attaches great importance to the development of an eco-compensation mechanism in river basins. In 2016, China issued the Guiding Opinions on Accelerating the Establishment of River Basin Upstream and Downstream Lateral Ecological Compensation Mechanism. It proposed that eco-compensation would be accelerated by applying water quality and water quantity benchmarks to a trans-boundary section of a river basin as a compensation benchmark and that this would promote the development of ecological civilization. However, due to the imperfect way in which the law was drafted, the lack of specific, operational mechanisms, and the diverse methods available, eco-compensation practices in river basins need to be further explored and supported.

Eco-compensation in the Xin' an River basin is the first, and most successful, interprovincial pilot in China so far. The compensation agreement was signed in 2012, and a three-year eco-compensation program was initiated. By the end of 2017, two rounds of pilot practices came to a successful conclusion. The water quality in the river basin was stable and improved, and economic development was maintained at a relatively fast pace with high quality. Public awareness of ecological civilization and participation in ecological and environmental protection had increased significantly. The linkage and coordination mechanism between the upper and lower streams of the river basin has been continuously improved, and the pilot targets have been fundamentally achieved.

\subsubsection{Application of NECA in Spatial Planning}

Internationally, a great number of research projects have been carried out using the value of ecosystem services as a reference for regional land-use scenario selection. Stephen et al. [24] quantitatively evaluated the change in ecological capital value and habitat caused by land-use change in Minnesota, United States, from 1992 to 2001 using environmental-economic accounting methods. They also simulated other landuse-change scenarios and comparatively analyzed the results. Research showed that landowners could only obtain the highest economic benefits when the farmland vastly expands, while other social benefits and ecological capital values were relatively lower. The results also showed that long-term land-use planning should consider not only direct economic returns but also the social and natural benefits included. Erik et al. [25] also used the InVEST model to evaluate and predict the change of ecological capital value in the Willamette River basin of Oregon, United States, when agricultural land takes up different proportions. They were able to provide valuable suggestions for land-use planning and decision-making in this area.

Zheng et al. [26] analyzed the relationships between provisioning and regulating ecosystem services and biodiversity protection. Taking the Hainan Ecological Function Protection Area as an example, they calculated changes in ecological capital value due to the large amount of rubber forest planting in this area from 1998 to 2017. The study showed that a $70 \%$ increase in the rubber planting area over the past 20 years had caused a decline in natural forests, reduced regulating ecosystem services, and 
destroyed large areas of wildlife habitat. The results showed that the damage costs and ecological benefits of ecological capital should be considered comprehensively in long-term land planning to maintain the balance between industrial crop supply and natural ecosystem health.

In May 2019, the Central Committee of the Communist Party of China (CPC) and the State Council jointly issued Opinions on Establishing and Supervising the Implementation of the Territorial Spatial Planning System (Opinions). This marked the formation of the top-level design of China's spatial planning system and a milestone in the process of China's historical planning. Opinions pointed out that the interrelationship between natural resources and economic development should be taken into account by the regulatory system and that the relationship between natural resources and economic development should be fully analyzed. In terms of the spatial governance system, it is necessary to build a protection system for territorial space to balance the relationship between ecological space, energy security, and food safety, and to achieve better preservation and appreciation of ecological capital through the protection of ecological space.

\subsubsection{Ecological Investment and Financing Based on NECA}

In addition to investments directly made by government financial funds, ecological investment and financing policies in the rest of the world have focused more on attracting private finance to participate in ecological environment protection through various means, including funds, bonds, and trusts. Government funds also tend to channel investment through funds and other financial means. Some developed countries have started to implement charging policies based on ecosystem services to increase ecological protection funds. At the same time, they also pay great attention to ecological investment and financing policies based on ecological and environmental benefits. For example, Land Retirement for Natural Resource Conservation in the United States compensates farmers that return farmland to forest, grassland, or farrow land. This project has achieved good results. One of the reasons for its success is the Environmental Benefits Index (EBI) introduced by the United States Department of Agriculture to comprehensively assess the environmental benefits of the rehabilitated land. The compensation standard has continuously improved based on the actual conditions.

China's ecological investment and financing policy system has been continuously improved in recent years. Especially since the 18th National Congress of the Communist Party of China in 2012, momentum has accelerated. The Decision of the Central Committee of the Communist Party of China on Some Major Issues Concerning Comprehensively Deepening the Reform adopted at the Third Plenary Session of the $18^{\text {th }}$ Central Committee calls for the establishment of a market-based mechanism to attract non-governmental investment for ecological and environmental protection. 
In September 2015, the Central Committee of the CPC and the State Council issued the Integrated Reform Plan Promoting Ecological Progress, defining the "Establishment of a Green Financial System" for the first time. The $13^{\text {th }}$ Five-Year Plan Outline clearly proposes the goal of "Building a Green Financial System," and this has become a national strategy. In July 2016, the Central Committee of the CPC and the State Council formulated and promulgated Opinions on Deepening the Reform of the Investment and Financing System, which established a series of specific arrangements for the government to deepen the reform of the investment and financing system, specifically for ecological and environmental protection and restoration. In August 2016, the People's Bank of China and other ministries jointly issued Guidelines for Establishing the Green Financial System, which marks China as the first country in the world to build a systematic green financial policy framework. Relevant ministries continue to innovate in the areas of fiscal, monetary, and regulatory policies related to ecological investment and financing, from the perspectives of green credit, green bonds, public-private partnerships, ecological compensation, etc. In addition, some local governments have also actively reformed policies and measures to innovate in the field of ecological investment and financing. For example, Huzhou city in Zhejiang province and Jiangsu province have introduced regulations to provide incentives in the form of reduced interest for green credit and green bonds.

\subsection{Challenges}

\subsubsection{A Lack of Standardized NECA Framework and Methods}

The connotation and concept of ecological capital are not unified. As a research field, NECA has a short history. Different scholars have diverse understandings of the connotation and the definition of related concepts. The concept and connotation of ecological capital are similar to the terms of ecological assets, ecological products, and ecosystem services. There are also overlaps and crossovers in the definition of assets or capital categories. The inconsistency of terms and concepts makes it difficult to compare results, despite having a large number of achievements in the academic field. The non-standardized accounting results also mean that they are difficult to promote and apply at the policy level, which directly affects the application of research results by decision-makers.

A lack of standardized accounting framework and methods. Although NECA has been carried out in the MA, the United Nations Experimental Ecological Account (EEA) and TEEB study, there are differences in accounting frameworks and methods used in different studies. One of the most important issues where there is a lack of consensus on the "Four Categories" approach proposed by the MA. This distinguishes four types of ecosystem services: supporting, provisioning, regulating, and 
cultural services. In its technical guidelines, the EEA advocates the use of a "Three Categories" approach that includes provisioning, regulating, and cultural services. At present, there is no consensus in national and international studies on using either of these approaches for accounting indicators. The indicators of both supporting services and regulating services are also not unified.

\subsubsection{Economic Development and Planning Decisions not Fully Reflecting the Value of Ecological Capital}

For quite a while, China's planning system has been extensive and complex. Since the implementation of integrated urban planning in a single scheme, the core of the planning system has become spatial planning with the goal of optimizing the allocation of territorial space and promoting social and economic development. However, at present, China's planning and decision-making system lacks the quantitative evaluation of the costs and benefits in order to achieve this objective. The planning and decision-making process also lacks guidance on the concept of sustainable development, which leads to unclear economic accounting of planning goals. As a result, the hidden costs and benefits related to ecological capital cannot be fully considered in planning and decision making. The lack of quantitative evaluation methods leads to the questioning of the scientificity and sustainability of planning decisions.

Meanwhile, the objective indicator system of national spatial planning has also lacked consideration of ecological capital. The indicators related to ecological capital are not included in the planning indicator system as binding indicators. Different types of ecological capital and the services they provide cannot be fully reflected in the planning process. The value of ecological capital cannot play a leading role in planning decisions, nor in the process of planning. The long-term absence of ecological capital value in planning has affected the balanced development of the overall layout of China's "Five-in-One" national strategy. The outcome of ecological civilization development, reflected in the increased value of ecological capital, cannot be fully achieved in the planning process.

\subsubsection{NECA not Fully Working for the EFM}

The pricing mechanism and trading rules of eco-products have not been established yet. Although China has made some progress in developing the pricing mechanism of eco-products, a unified standard procedure has not yet been formed. This leads to the subjectivity and arbitrariness of some NECA, further affecting the authority of assessment results. At the same time, the regulations regarding the eco-product market, which includes an eco-products value realization mechanism, market permits 
and allocation, as well as the management of relevant stakeholders, are lacking standards, which impedes the implementation of a trading mechanism for eco-products. There are also technical obstacles to incorporating the results of NECA into the financial and investment system. Furthermore, it is difficult to carry out financing operations by using mortgage loans, green bonds, and green funds, which is unfavourable for green development.

The evaluation system and tools of green financial products based on NECA are in great demand. The consideration of ecological capital is missing during the decisionmaking process for financing projects, which still treats the natural environment as an unvalued factor of production without considering the "capital" attributes of the natural environment. As a result, it becomes difficult for investors to identify green investment projects or to design projects to protect or enhance natural capital. Moreover, it fails to stop investors from providing credits or funds to enterprises that seriously pollute the environment and have no possibility of reaching emission standards. Without such consideration, it is also difficult to help other green projects, including environmental remediation, contaminated site restoration, and ecological conservation, to obtain investment. This makes it difficult for the green industry to develop through the capital market, which further seriously restricts the development of green investment and EFM.

\subsection{Chinese Experience and Emerging Best Practices}

\subsubsection{Ecological Bank: Wuyishan City}

Located in the northwest of Fujian province, Wuyi Mountain is one of China's 11 key areas for biodiversity conservation in features of global significance and the only one in the southeast region. Wuyi Mountain was listed as a world heritage site by UNESCO in December 1999. Within national KEFZs, Wuyishan City undertakes important ecological functions, such as water flow regulation, mass flow regulation, and biodiversity maintenance, which are crucial to the ecological security of Fujian province. In 2017, Wuyishan City piloted the NECA tasks designated under the Implementation Plan of the National Ecological Civilization Pilot Zone (Fujian). The accounting results indicated that, in 2010 and 2015, the total value of ecosystem services in Wuyishan City was 183.09 billion RMB and 221.99 billion RMB, respectively. The value of ecosystem services achieved 27.8 and 16.0 times the city's GDP, depending on the accounting methods adopted.

In 2017, Nanping where Wuyishan City is located, released The Pilot Implementation Plan of "Eco-Bank." The Wufu township of Wuyishan City was set as the location of the pilot. Through the exploration and innovation of natural resources management, evaluation, circulation, and transaction, a typical path was formed to transform the advantages of ecological resources into economic benefits. The operation process of the "eco-bank" model includes three stages: acquisition and storage 
of resources, consolidation of assets, and introduction of invested capital. Among them, resource acquisition and storage includes two modes: actual acquisition and storage and pre-storage. The "actual acquisition and storage" refers to the collection and storage of scattered and fragmented resources into the "eco-bank" operating platform or the natural resources bureau of Wuyishan City, the government of the Wufu township, and the villages. Natural resources are collected by means of resource purchasing, circulation, leasing, mortgage loan of the right to use, share cooperation and trusteeship, etc. "Pre-storage" refers to the use of the Wufu Township Ecological Resources Registration Card issued by the "eco-bank" to register their private ecological resource development expectations, including information on the acquisition and storage method, purchase and storage price, purchase and storage period, and purchase and storage use of these resources at the "eco-bank" operation company. This is run through the town government's service centre, which will be included in an Ecological Resources Map and the eco-bank can only be used when it conforms to the control requirements of city and town planning.

The Eco-Bank of Nanping City is not a financial institution, but a natural resources operation and management platform. By making an Ecological Resources Map, the fragmented ecological resources are centrally acquired, stored, renovated, and converted into contiguous high-quality and efficient resource packages and entrusted to operators to realize the transformation of resources into assets and, finally, capital under the premise of ecological protection. The ultimate purpose of the eco-bank is to realize the transformation of resources into assets and capital and to allocate high-quality and environmentally friendly green industries through the connection of green industries to the capital market.

\subsubsection{Voluntary Carbon Emission Reduction and Public Welfare Tree Planting: The Ant Forest}

The Ant Forest, launched in August 2016, is an application on the Alipay platform developed by Ant Financial of the Alibaba Group. All registered users will get a virtual tree, which can be cultivated by obtaining energy values through personal daily low-carbon practices. When the virtual tree is fully grown, Ant Financial will plant a real tree in the real world. By August 2019, 500 million users in Ant Forest had reduced carbon emissions by 7.92 million tonnes and planted 122 million real trees, creating a green area the size of 1.5 Singapores, according to the Report on Public Low-Carbon Lifestyle in the Context of Internet Platforms. At present, Ant Forest's protected areas are mainly concentrated in Heshun of Shanxi Province, Pingwu of Sichuan Province, Yanghu of Huangshan City, Deqin of Yunnan Province, Wangqing of Jilin Province, Yangxian of Shaanxi Province, and Kuubuqi of Inner Mongolia, among others.

Alipay incentivizes consumers to use its services by rewarding their behaviour with a tree-planting scheme. Users will generate a green energy value representing 
Table 5.1 Partial green energy value comparison

\begin{tabular}{l|l}
\hline Green behaviours & $\begin{array}{l}\text { Green energy values (carbon dioxide emission } \\
\text { reduction) }\end{array}$ \\
\hline $\begin{array}{l}\text { Online Ttcket purchase (including movie } \\
\text { tickets and performance tickets) }\end{array}$ & $180 \mathrm{~g}$ \\
\hline Walk steps & $296 \mathrm{~g}$ (Maximum) \\
\hline Offline payments & $5 \mathrm{~g}$ per purchase \\
\hline $\begin{array}{l}\text { Living consumption (Including water, } \\
\text { electricity, gas and etc.) }\end{array}$ & $262 \mathrm{~g}$ per purchase \\
\hline Online train ticket purchase & $277 \mathrm{~g}$ per purchase \\
\hline Subway & $52 \mathrm{~g}$ per ride \\
\hline Bus & $80 \mathrm{~g}$ per ride \\
\hline Second-hand goods trade on idle fish & $790 \mathrm{~g}($ Maximum) \\
\hline $\begin{array}{l}\text { Choosing no cutlery for takeout orders from } \\
\text { Ele.me }\end{array}$ & $16 \mathrm{~g}$ \\
\hline
\end{tabular}

Note At present, more than 10 kinds of saplings can be planted by Alipay, such as ammodendron, camphor pine, populus euphratica, and salix. The amount of green energy required to plant a certain type of tree ranges from 16,390 to $22,400 \mathrm{~g}$

their carbon dioxide emission reduction after they practice low-carbon behaviours such as offline payment via Alipay, online payment for living consumption, online ticket purchase, appointment booking, applying for electronic invoicing, and taking a walk. However, green energy is not generated immediately. It can only be generated the day after the user completes the green behaviour. The green energy will automatically disappear if it is not collected by the user within three days (Table 5.1).

Ant Financial has three expansion plans regarding the Ant Forest. The first plan involves improving and standardizing the calculation method of carbon dioxide emission reduction through either cooperating with Beijing Environment Exchange and other institutions to standardize a personal carbon footprint algorithm or working with the UN Environment Programme to transform the calculation method to international standards, which will be promoted and applied to other payment platforms to jointly practice carbon emission reduction. The second step is to set up an open green platform to realize personally centred carbon emission calculation methods for enterprises and non-governmental organizations (NGOs) and turn emission reduction into projects related to environmental protection, such as tree planting and water conservation. The final plan is to build a multi-purpose green finance platform to help small and medium-sized enterprises to enter the carbon trading market and reward their carbon reduction activities; assist small and medium-sized enterprises and individuals in conducting offline transactions outside of the market; establish a certification system for green products; and develop green financial tools to support the green investment and financing industry. 


\subsubsection{Forest Coupon System: Chongqing City}

In recent years, Chongqing has maintained ecological and green development priorities, vigorously implementing ecological protection and restoration initiatives. According to the Action Plan for Implementing Ecological Priority Green Development in Chongqing (2018-2020), a total of 17 million acres of forest will be planted between 2018 and 2020, and the city's forest coverage rate will increase to $55 \%$ by 2022 . In October 2018, the General Office of the Chongqing Government issued the Work Plan for Implementing Horizontal Ecological Compensation to Improve Forest Coverage in Chongqing (trial), exploring a PES mechanism based on forest coverage. In order to achieve the goal of afforestation, Chongqing started the construction of a forest coupon trading mechanism on the basis of a land coupon trading pilot combined with PES.

Chongqing divided its 38 districts and counties into four categories and assigned target tasks accordingly. Among them, the forest coverage rate of major grainproducing counties and major vegetable oil-producing areas (except the national KEFZ) is $45 \%$. After deducting the transaction index, the forest coverage rate of districts and counties that are eligible to sell the forest area index shall not be less than $60 \%$. The Chongqing Forestry Bureau regulates the overall transaction price, stipulating that the subsidy for afforestation per acre should not be less than 1,000 RMB, which can be paid in a lump sum or in installments before 2022. At the same time, the corresponding area of forest management and protection expenses, which shall be no less than 100 RMB per acre per year, should be paid as well for at least 15 years of management and protection. In March 2019, the Jiangbei District of Chongqing and Youyang Tujia and Miao Autonomous County signed the first PES agreement based on forest coverage.

Under the principle of occupation and compensation balance, the forest coupon trading system encourages landowners to voluntarily develop construction land or unused land into qualified forest land, which will be issued an evaluation report by third-party professional institutions. The local government will eventually issue a forest coupon according to the quality and area of forest land. Through the trading platform built by the government, the coupon is transferred to the occupier of the forestland with compensation in the way of market bidding. Only after the occupier obtains enough forest coupons can it purchase the right to use the corresponding amount of land for development and operation.

\subsubsection{Green Investment and Financing Policy Practice: Quzhou City of Zhejiang Province}

Since the successful approval of the national green finance reform and innovation pilot zone in 2017, Quzhou City of Zhejiang province has established a green standard 
evaluation system and a factor priority guarantee supply mechanism, actively guiding financial capital to upgrade traditional industries.

A green finance standard system has been developed that suggests the following steps. First, take "finance supports for the green transformation of traditional industries" as the guideline, compile the evaluation methods for green projects and green enterprises, and guide social capital to increase support for the transformation and upgrading of traditional industries, the happiness industries of a beautiful economy, and the smart industries of the digital economy. Second, raise the standardization of comprehensive liability insurance services for production safety and environmental pollution to provincial standards. Third, be proactive in carrying out a quality assessment of special statistical data on green loans to achieve the unification of local standards for green credit. Fourth, take the lead in establishing green banking system standards for local legal entities. This Quzhou model produces a group of green financial products.

The first step to creating green credit in the Quzhou model is to develop green credit products such as pledge loans for intangible assets, environmental rights and interests and receivables, seamless loan renewal, investment-loan linkages, debtto-equity swaps and debt-to-equity combination. The second step is to innovate the Quzhou model of green bonds by actively exploring the combination model of government industrial funds and private convertible bonds and then issue the first private green entrepreneurship and innovation convertible bonds in China. Then, actively issue green financial bonds to support local green projects. Quzhou City launched a special program called One Point Carbon Turns Green to Gold, which innovates an ecological compensation and forestry development mechanism through forestry carbon sink trading. The third step of the Quzhou model is developing green insurance. China's first comprehensive liability insurance for production safety and environmental pollution established the comprehensive insurance service mechanism of "insurance + process management." It developed China's first joint mechanism of pig insurance and harmless treatment to solve the environmental pollution of livestock from the source and pioneered comprehensive liability insurance for electric bicycles. Fourth, explore the "giant model" of green finance to support the transformation and upgrading of traditional enterprises and accelerate the green transformation of traditional chemical industries.

The Quzhou model also developed a green finance approval process system. Quzhou focuses on rebuilding the green credit approval process in the city's agricultural credit system and plays an exemplary leading role. At the same time, it encourages and guides commercial banks to set up separate green finance departments, independent green credit approval channels, separate green credit scales, and a green credit assessment and incentive system, all of which have received extensive responses and achieved positive results. 


\subsubsection{Green Finance Standard: Gui'an New Area of Guizhou Province}

Gui' an New Area of Guizhou province is the first approved green financial reform and innovation experimental zone in Southwest China. In recent years, it has actively explored innovative green financial standards and assessment systems and mechanisms, issued a Guizhou Province Green Finance Projects Standard and Evaluation Method (trial), and clarified green financial project assessment criteria and procedures. Guizhou Province Green Finance Projects Standard and Evaluation Method (trial) is composed of two parts: Guiding Standards for Key Green Finance Support Industries in Guizhou Province (trial) and Evaluation Methods for Major Green Projects Supported by Green Finance in Guizhou Province (trial).

On the basis of the Green Industry Guidance Catalogue (2019 edition) issued by seven ministries and commissions, including the National Development and Reform Commission, Guizhou Province Green Finance Projects Standard and Evaluation Method (trial) has been improved and enriched from the aspects of financialization, localization, practicality, and internationalization. From the perspective of industry selection, according to the industrial characteristics of Guizhou province, key green industries are selected from the Green Industry Guidance Catalogue (2019 edition), and green industries with the characteristic of Guizhou are appropriately increased, such as ecological tourism, biodiversity protection, the green data centre, maintenance and management of arable land and soil, fertilizer and water speed measuring technology development and application, green transportation, green public transportation, etc. In terms of standard form, it gives priority to quantity and takes quality as complementary; in terms of presentation, the "index system method" is adopted to clearly characterize the green financial standards and characteristics of various industries. For example, the green data centre adopts the standards promulgated by the Ministry of Industry and Information Technology that the energy use efficiency of new large and super-large data centres has significantly improved through electricity transformation. The Hong Kong Quality Assurance Agency Green Finance Standard, standards related to the Equator Principles, and a number of internationally recognized industry standards have been added to attract international green finance funds.

According to the investment amount of green technology, the level of technology, the comprehensive eco-environmental benefits, and the replicable and popularizing value of green financial innovation, etc., Guizhou Province Green Finance Projects Standard and Evaluation Method (trial) lists projects that are of great significance to the protection of the ecological environment and the innovation of green finance that can be replicated and promoted as major green projects. Mainly major green projects will be evaluated, supported, and promoted, with supporting policies including but not limited to financial incentives, policy support, priority review, and financial support.

At present, the green finance project bank of Gui' an New Area has absorbed more than 1,000 projects in Guizhou Province and Southwest China, with the project financing demand reaching more than 400 billion RMB. It has successfully launched 
the distributed energy project supported by green asset securitization called Two Lakes and One River, the Guiyang metro line S1 project, and other projects, in cooperation with financial institutions.

\subsubsection{Ecological and Environmental Damage Compensation: China}

Since 2018, when China launched a pilot reform of the compensation system for ecological and environmental damage, the principle of Taking Responsibility for Damage and Valuing the Environment has been implemented. After a two-year nationwide trial, it has effectively promoted the restoration of the damaged ecological environment and paid compensation in cash for the damage that could not be repaired. While solving the dilemma of the public becoming victims of pollution caused by enterprises while the government is paying the bill, it accumulated funds for compensation for ecological environment damage. So far, 942 cases of ecological and environmental damage compensation have been handled, involving compensation of about 2.5 billion RMB. More than 12.09 million cubic metres of soil, 19.98 million square metres of forest land, 6.05 million square metres of grassland, 42.23 million cubic metres of surface water, and 460,000 cubic metres of underground water have been repaired. About 227.92 million tonnes of solid waste has been cleaned up. There are some typical cases selected:

\section{(1) Hazardous Waste Dumping in Haide, Jiangsu Province}

In 2014, a company repeatedly entrusted unqualified personnel to dispose of hazardous waste, resulting in more than 100 tonnes of waste lye being dumped into the Yangtzerriver, causing serious water and environmental pollution. The parties bore criminal responsibility and were sentenced and fined between 10,000 RMB and 2.58 million RMB. After the criminal case was concluded, the People's Government of Jiangsu Province filed a claim with the people's court as the obligee of compensation, and the enterprise undertook fines of 54 million RMB to repair the damaged ecological environment.

(2) Ecological Environmental Damage Compensation in the Dabusu Nature Reserve

In 2005, a company started an oil recovery project in the core and buffer areas of Dabusu Nature Reserve without approval. Due to long-term oil exploitation, the soil and vegetation in the reserve area have been damaged. In 2018, the People's Government of Jilin Province, as the obligee of compensation, made a compensation request with the company for ecological and environmental damage. Based on the environmental damage assessment and suggestions for restoration, the two sides reached an agreement on ecological and environmental damage compensation. Jilin Oilfield Company entrusted a third party to prepare the restoration plan for the ecological 
and environmental damage caused by illegal mining and organized the restoration work by itself. After the completion of the restoration, the environmental authority evaluated the result of restoration. In addition, the company paid 2,303,600 RMB for the loss of service function during the ecological and environmental restoration. The damages are transferred to the financial account designated by the compensation right holder and used as the non-tax income of the provincial government, which is handed over to the Provincial Treasury and managed according to a provincial financial budget.

(3) An ecological restoring park instead of atmospheric emission violation in Shaoxing City, Zhejiang province

An enterprise in Zhejiang province interfered with automatic monitoring data and illegally discharged air pollutants. After negotiation, the enterprise not only paid 1.1 million RMB for air pollution damage compensation but also voluntarily added 1.76 million $\mathrm{RMB}$ to build an ecological park in the village where the damage occurred. In this case, the polluters improved the ecological environment by building the ecological park, which enhanced the surrounding villagers' sense of a gain in environmental improvement.

In summary, for the first case, in which damage to the ecosystem cannot be fixed, compensation by money is the only solution. In the second case, the damage is partially repaired and additionally compensated with money. The third case adopts an alternative restoration plan to achieve eco-environmental protection. It should be noted that, at present, the Ministry of Finance plans to integrate eco-environmental damage compensation and fines from environmental public interest litigation into the fiscal budget management at all levels but cannot allocate the fund to address eco-environmental restoration needs specifically. How to efficiently utilize this fund is an urgent problem and remains unsolved.

\subsection{International Experience and Emerging Best Practices}

\subsubsection{Gender as a Factor in Ecosystem Services: Nepal and Kenya}

Nepal: Ecosystem services protections for women and vulnerable groups need to be carefully designed so as not to create additional burdens. Chaudhary et al. [27] examine provisions that are intended to ensure social equity but find that high-income groups are still able to disproportionately access the benefits of ecosystem services. In particular, the authors note that these provisions place additional burdens on the groups they sought to help. The policy of imposing fines on those who do not participate in community forestry meetings is intended to encourage the participation of marginalized groups. However, these groups have both the least capacity to attend meetings and the most difficulty paying fines. 
Kenya: A randomized trial demonstrates that, for PES schemes to be equitable, they must consider the relative status of women in a given context and overcome cultural and economic barriers. Examining a randomized trial that utilized auctionbased contracts, Andeltová et al. [28] find that women tend to be relatively more risk averse than men and theorized that this is likely due to women's significantly lower income in this context. The authors also observed that the trees planted by woman have lower survival rate than men, despite women working harder, and argued that this is due to inequality in reciprocal labour between men and women. The authors argue that targeting women in PES schemes can improve gender equity by granting them greater access to decision-making, training, and cash. Andeltová et al. [28] also argue that the participation of women in these schemes can significantly improve the schemes' effectiveness.

PES can economically empower women if deployed in a context-sensitive approach. In an examination of agroforestry schemes with PES in sub-Saharan Africa, Benjamin et al. [29] find that female participation "reduced profit inefficiency," which contributes to economic empowerment. The authors suggest that agroforestry schemes with PES have the potential to empower women in sub-Saharan Africa if they target poor female smallholders.

Access to education is gendered and plays a central role in determining who benefits from ecosystem services. In a study of landowners in Brazil, Lima and Bastos [30] found that years of formal education has a significant impact on whether an individual perceives the value of ecosystem services that are considered to be more difficult to observe (e.g., pollination and pest regulation).

Accounting for gender in ecosystem services is likely to result in the prioritization of different services, which in turn could lead to different outcomes for livelihoods. In a study of nine Indigenous communities in the Colombian Amazon, Cruz-Garcia et al. [31] compared the ways in which men and women value ecosystem services. In the study, services such as land for agricultural fields and the provision of fish and medicinal plants were equally important to both men and women. However, while women tended to consider wild fruits and resources to make handicrafts as important, men more frequently mentioned timber, materials for making tools, and coca leaves. In their examination of the Fijian men's and women's perspectives on the use, benefit, and value of mangrove ecosystems, Pearson et al. [32] found that women and men in Fiji valued the ecosystem services provided by mangroves differently, based largely on the traditional gender-specific tasks to which they were assigned. The authors call for a gender-sensitive valuation framework of ecosystem services to ensure that the decision-making process is inclusive. 


\subsubsection{Natural Capital Management Experiences: United Kingdom}

Implementing a natural capital approach: The work of the Natural Capital Committee. Over the last decade, the United Kingdom (U.K.) government has introduced a set of ambitious policies to protect and enhance natural capital. This has put the U.K. at the cutting edge of efforts to advance the conceptual, empirical, and practical policy approaches needed to better manage natural capital. However, despite these good efforts, results have fallen short of ambitions. Some limited progress has been achieved in some areas, but, in many others, the state of the environment has continued to deteriorate. Ecosystems remain fragmented. The difficulties inherent in developing a robust evidence base to guide policy has been a major obstacle. Equally, policy implementation has been impeded by the failure of the U.K. government to provide the legal, institutional, and financial means to achieve its ambitious policy objectives.

In 2012, the U.K. government established the Natural Capital Committee (NCC). During its first phase of work, the NCC identified the key elements that it considered necessary to support the elaboration of a coherent strategy for protecting and enhancing natural capital. It also elaborated key policy principles to guide the development of a natural capital approach and recommended that pilot projects be implemented in order to gain experience in applying a natural capital approach in different areas and circumstances. The NCC considered that there were three basic foundations on which a better strategy for managing natural capital should be based: measurement, accounting, and valuation. In addition, the NCC argued that a framework was needed to identify and prioritize actions. The framework should address not only actions to protect nature in the future but also actions to reverse historic losses in natural capital. In 2017, the NCC produced a workbook to help decision-makers to implement a natural capital approach. It synthesized some of the NCC's main findings and referenced tools and sources that could assist planners, communities, and landowners to make place-based decisions to protect and enhance natural capital.

Natural capital accounts. In 2011, the government committed Defra and the Office of National Statistics (ONS) to incorporating natural capital into the U.K. Environmental Accounts by 2020.

Measuring natural capital. In 2014, the NCC proposed a framework for defining and measuring natural capital.

Prioritization framework. In its 2015 report, the NCC considered accurate measurement, accounting, and robust economic valuation to be essential for implementing a natural capital approach. It argued that a commitment to reverse historic losses in natural capital was also required. To this end, the NCC proposed a framework for identifying and prioritizing actions organized around three questions: How much natural capital is needed and what targets should be adopted? Which natural assets and benefits need urgent action? How should priority action be determined? 
Natural capital valuation. In 2017, the NCC published a guide to natural capital valuation. The NCC considered that the failure to adequately value the full economic costs and benefits of natural capital assets in public and private decision making was a key factor in their deterioration.

Financing the protection and enhancement of natural capital. While the provision of mechanisms to finance investments in natural capital is important, government policies and institutional arrangements can provide important incentives (and disincentives) for such investments. In the U.K., some of the main policy approaches that are in operation or under consideration include:

- Replacing European Union subsidies for agriculture, which have often intensified pressures on natural capital with a system targeting public goods and promoting a better market for environmental goods and services.

- Establishing an "environmental (or biodiversity) net gain" principle for development projects.

- Integrating nature-based approaches into flood management schemes.

- Establishing a domestic carbon offset program that helps to create a market for carbon sequestration, e.g., tree planting.

- Product certification schemes.

During preparations of the 25 Year Environmental Plan [33], Defra compiled information on the main sources of finance for natural capital. The 2019 State of Nature report also examined financing for conservation. Defra found that most investments in the U.K. had been provided as subsidies or grants from the European Union, central and local authorities, philanthropic organizations, and the national lottery. Central government spending was estimated at $£ 805$ million in 2015-16. The 2019 State of Nature report's estimate was lower; it concluded that public sector spending on biodiversity in $2017-18$ was $£ 456$ million, a decline of about a third from a high point in 2008-09.

Defra estimated that spending by non-governmental environmental organizations with a nature or biodiversity objective was $£ 236$ million in $2014-15$, and support from the national lottery was about $£ 100$ million per year. The 2019 State of Nature report's estimate was similar: NGO expenditure on biodiversity and conservation amounted to $£ 239$ million in $2017-18$, an increase of about one quarter over five years. This report also stressed the importance of volunteer work, estimated at 7.5 million hours to support the preparation of the State of Nature report. The authors concluded that "although financial investment is crucial, as are government policy and legislation,....the most successful conservation action arises from partnerships, across governments, charities, business, landowners and individuals working together." 


\subsection{Accelerating and Scaling up Solutions}

\subsubsection{Design Unified Standards for Eco-Products Valuation}

To establish a unified classification and pricing standard for eco-products, several steps must be taken, including:

- Further strengthening the study on the classification of eco-products.

- Harmonizing the existing classification system of eco-products adopted by the Ministry of Ecology and Environment, the Ministry of Natural Resources, and the National Development and Reform Commission with corresponding international guidelines to identify and analyze the concept, connotation, and scope of ecoproducts.

- Preparing a classification guide of eco-products in different regions using the main ecosystem types in different regions of China in order to guide the classification and indexation of eco-products.

- Carrying out an analysis of international and national NECA results, including international and national market prices for the same eco-products produced in different areas, to try to establish a price mechanism model of eco-products that could lay the foundation for forming the pricing standard of eco-products.

It is critical to factor in the valuation effects based on gender and vulnerable populations.

Gradually improve the ecological capital accounting methods system. At present, the framework and methods of NECA are not unified and the technical parameters needed to characterize regional ecological systems are lacking. Therefore, we recommend the adoption of two approaches for valuing ecosystem services: a bottom-up valuation of ecosystem services and a top-down equivalent factor method based on macro measurement results. The aim is to establish the assessment framework, accounting method, and technical parameter system of NECA at the regional, watershed, and national levels for different purposes. There is also a need to clarify the application of different accounting methods, to guide various regions to carry out eco-product valuation within a unified framework, and to provide technical support for the standardization of eco-product value.

\subsubsection{Establish and Unify the Concept and Rules of an Ecological Financing and Investment Mechanism (EFM)}

Further define and unify the concept and connotation of ecological investment and financing. In order to distinguish eco-financing from green financing, and to 
accurately reflect the status of EFM in China's ecological environment protection system and its driving effect on economic growth, we need to clearly define the concept of EFM needs. Responsibility for the indicators related to EFM was allocated to relevant governmental departments, which would jointly promote the design, revision, implementation, dissemination, supervision, and management of standards in key areas of EFM, such as securities, insurance, environmental rights and interests, and trading, to ensure the unity and universality of the standards.

Establish determination and evaluation rules for ecological investment and financing. Based on the valuation results of ecological capital and eco-products, work should be carried out to explore and formulate a universal and unified catalogue of ecological investment and financing sectors and specific projects. Regional authorities should be encouraged to produce regional standards such as Evaluation Criteria for Ecological Investment and Financing Projects, Evaluation Criteria for Ecological Investment and Financing Enterprises, and Specifications for the Construction of Ecological Finance Franchise Institutions, as well as other guidelines that could be widely applicable in banks and other financial institutions dealing with bonds, credit, stocks and funds. The catalogue of ecological investment and financing sectors and projects should comply with the overall requirements of national ecological civilization development as well as development trends of the green industry system. They should clearly specify the scope and key areas of ecological investment and financing projects.

\subsubsection{Carry Out Planning and Project Cost-Effectiveness Analysis Based on NECA}

Establish a planning methodology that comprehensively considers the protection and enhancement of ecological capital and the related economic benefits. The ecological capital background of the targeted region or watershed should be mapped, and the major ecosystem services and associated economic benefits they provide should be evaluated. This information should be integrated into the objective indicator system of spatial planning, with an awareness of the gendered characteristics of the value of resources. Research should be carried out on the valuation of eco-product provisioning, ecosystem regulation, and culture services under different planning scenarios, as well as on the associated economic cost-benefit analysis during the planning stage. A cost-effectiveness analysis should be used during planning to ensure that the approach chosen protects or enhances ecological capital at the least cost.

Require cost-effectiveness analysis for ecological investment and financing projects. This should apply to the different types of ecological investment and financing projects, such as the ecological restoration and environmental treatment of mountains, rivers, forests, farmlands, lakes, and grasslands, mines, and river basins. 
The external impacts on and benefits of ecological capital should be comprehensively considered within the project life cycle. Research should be carried out on the ecological and environmental life cycle impacts of ecological investment and financing projects, including the preparation of an inventory of impacts and a scenario analysis. A breakthrough is needed to establish the framework and technical methods of NECA for the management and ecological restoration of river basins. Fundamental data should be collected as well as the technical parameters of water flow regulation, climate regulation, water and soil conservation, biodiversity conservation, and other ecosystem services involved in different types of watershed and wetland construction projects. Technical guidelines should be prepared for the cost-effectiveness analysis of projects for the ecological restoration of river basins, and support should be provided for optimizing project decision making.

\title{
5.7.4 Strengthen the Design of Ecological Investment and Financing Policies
}

\begin{abstract}
Promote the integration of ecological capital into the design of ecological investment and financing policies. When designing ecological investment and financing policies and mechanisms, we should consider not only the goal of economic benefit as traditionally defined but also the goal of ecological protection and the implications based on the gendered use of resources. We should comprehensively evaluate the cost of supplying eco-products and the benefits of providing those services at different scales by using NECA as a quantitative assessment tool for investment and financing decision making. We should determine whether the design of ecological investment and financing policies and mechanisms are sustainable by comparing the changes in the stock of ecological capital and other capitals. We should continuously revise ecological investment and financing policies to improve the reliability of decision making based on the evaluation of these changes.
\end{abstract}

Establish a performance evaluation system of ecological investment and financing projects based on NECA. Taking an ecological and environmental performance perspective, NECA should be combined with the existing project performance evaluation system. First, the existing performance evaluation should be appropriately adjusted based on changes in the provision of ecosystem services. It should be applied flexibly based on activity type, and the implications should be based on the gendered use of resources. How project funds are used should objectively and fairly evaluate the effectiveness, efficiency, and benefits. The evaluation should strengthen ecological protection and restoration, improve the quantity and quality of ecological capital, and enhance the capacity to supply eco-products through the means of PES, property transaction, ecological industrialization management, etc. 


\subsection{Governance and Implementation}

In future development, the application of NECA and ecological investment and financing policy should be divided into different stages according to the extent of urgency and difficulty.

Short-term plan (2020-2023): First, raise public awareness. Through the media, make the public generally aware that ecological capital is not only valuable but also closely related to the interests of everyone. Foster awareness that protecting ecological capital could increase its value and the return on investment. Second, standardize NECA. The frameworks for accounting, applying, investing, financing, and trading ecological capital should be established under a unified methodology, indicator, and valuation system. In order to better promote NECA and its application in various policies and planning, the standardization of NECA should be studied to make the accounting results comparable at both regional and time-frame levels. Third, further improve capacity building. Officials of the relevant government departments at all levels should be trained in and certified to use NECA to implement ecological investment and financing policies. Local governments should be encouraged to set up ecological cloud information platforms, share basic accounting data, and design automatic NECA systems to ensure the sustainable advancement of working practices.

Medium-term plan (2024-2026): First, promote pilot projects. Apply and disseminate the standardized framework and methods of pilot studies to more regions, so as to form a mature NECA method and pricing system. Second, promote the application of NECA in the policy fields of ecological investment and financing and spatial planning. Improve the design of relevant ecological investment and eco-products' financing policies by establishing an eco-products trading market and its operational mechanism. Carry out an analysis of national spatial planning and decision-making based on NECA to strengthen the optimal allocation of land and resources. Establish regulatory mechanisms for NECA and EFM to support comprehensive decisionmaking by governments at all levels. Third, strengthen the application of NECA at a strategic level. Promote NECA and EFM innovation to support national strategic plans such as the Belt and Road Initiative, development of the Yellow River basin and YREB, etc. Provide methods and policy guidance for national strategic development regions such as Beijing-Tianjin-Hebei and Great Bay Area.

Long-term plan (2027-2035): Form a complete NECA and ecological investment and financing system. Adapt top-down government institutional reform by continuously improving ecological capital management. Establish working mechanisms for coordinating socioeconomic development with the comprehensive management of ecological capital and ecological environment quality. Mainstream NECA and ecological investment and financing policies into decision-making processes at all government levels (Fig. 5.1). 


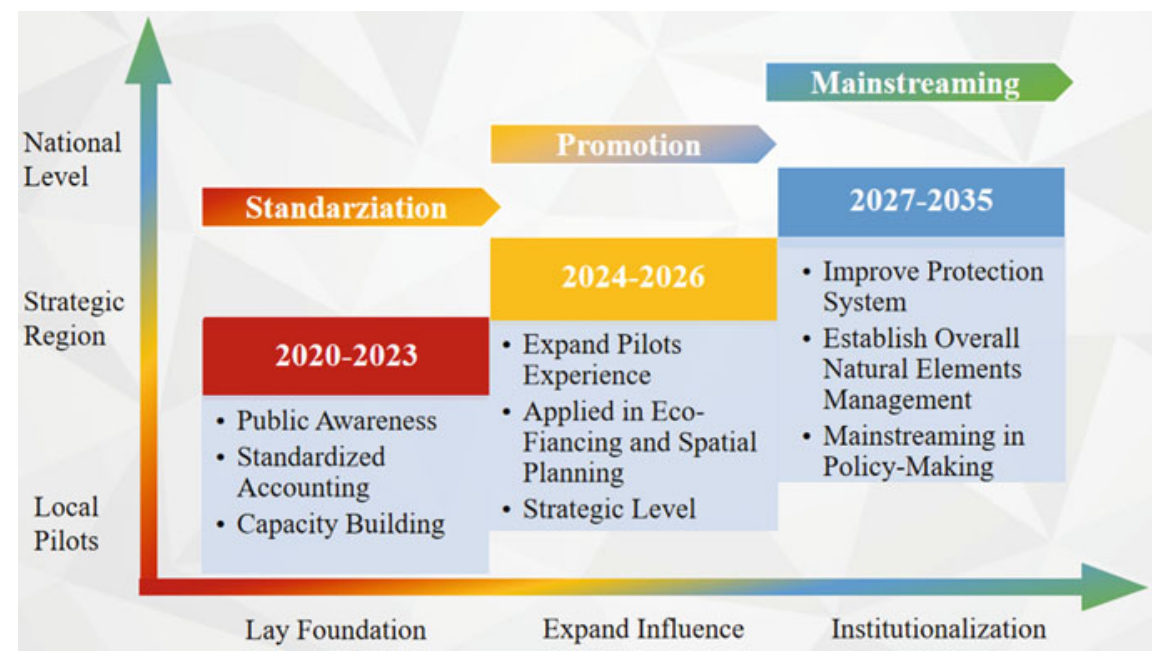

Fig. 5.1 Governance and implementation roadmap (2020-2050)

\subsection{Recommendations}

\subsubsection{Accelerate the Promotion of NECA and Its Policy Application: Unifying Values Through Standardization}

At present, the basic concepts of ecological capital and eco-financing have not reached a mutual agreement. The accounting framework and accounting methods carried out around the world have not been unified. The unstandardized accounting results are making it difficult to apply the results at the policy level due to a lack of comparability. Take the lab-initiative as the carrier, promote the standardization of the accounting framework and methods, integrate the mechanisms and process parameters of different regions and different types of ecosystems, and form an integrated regional solution consisting of basic data, quantitative accounting, scenario simulation and policy innovation. This approach also provides the support for eco-product transactions and eco-financing mechanisms at the national level.

\subsubsection{Establish a Normative and Standardized NECA System to Provide a Basis for Value Realization}

Form a NECA framework system. On the basis of NECA research experiences so far, an international NECA committee jointly organized by international organizations such as the United Nations Statistical Division, the World Bank, and 
ADB etc., is proposed to: (i) provide basic information and agreement on essential concepts and connotations such as stock accounting and flow accounting; (ii) propose accounting frameworks for provisioning services, regulating services, cultural services, and/or supporting services in different application scenarios; and (iii) explain and standardize the applicability and basic data requirements of different accounting methods.

Publish technical guidelines on NECA. To comprehensively summarize the specific practices of NECA in different regions, form a standardized and unified technical guideline for NECA that clearly defines the principles for indicator selection for different application scenarios and makes uniform stipulations on professional terms, accounting indicators, applicable models, data sources, and technical parameters, etc. The standardization of NECA methods provides an approach to the comparability of accounting results between different regions and the applicability of costeffectiveness decisions. It will also serve to standardize cross-regional transactions of eco-products.

Promote the development of an ecological resources monitoring network. Establish an ecological resource monitoring network that coordinates national technical standards, regional and river basin technical supervision, local promotion and implementation, and community participation. Promote the standardization of a monitoring network that combines multi-source remote sensing and ground observation of ecological resources to form a comprehensive survey and monitoring coverage on forest, grassland, wetland, farmland, oceans, minerals, water resources, and other important ecological elements. This will finalize data sharing, verification, and a working mechanism for cross-industries, cross-regions, cross-sectors, and the various stakeholders that participated.

\subsubsection{Establish a Lab Initiative for NECA and Policy Planning to Provide Tools for Accurate Policy-Making}

Develop a standardized NECA platform. Summarize various types of statistics, surveys, inventory, remote sensing and monitoring data from the ecological resource monitoring network. Propose principles on data selection and cleaning as well as the selection standards for accounting model tools to establish a fundamental database for NECA. The database will cover the structure, quantity, quality, and spatial distribution of land, forests, grasslands, water resources, and biological resources, etc. Integrate NECA model tools and the technical and value parameters required for the calculation of different types of ecological services to form a NECA model tool base that enables the ecological capital accounting functions on both physical and monetary perspectives. 
Develop a decision-making consultation platform based on NECA. Clarify the simulation model, methods, and data requirements of eco-financing policy plans such as bonds, funds, eco-product trading, PES, spatial planning, effects and postevaluation analysis, etc. Develop a policy and planning decision-making methods base; each of these methods needs to factor in gender and vulnerable populations. Propose technical guidelines for cost-effectiveness analysis at the policy, planning, and project levels. Clarify the ecological services, ecological service accounting methods, applicable parameters, and economic benefit accounting methods for different types of projects. Develop corresponding cost-effectiveness analysis tools to form a comprehensive platform for policy and planning simulations and ecological capital institutional innovation.

Establish a national NECA and policy planning simulation lab. With NECA as the core, set up a national-level NECA and policy planning simulation lab that is crosssectoral, cross-disciplinary, and cross-domain. The lab should have clearly functional divisions between its institutions and initiate working mechanisms, including data sharing, information disclosure and dissemination, and multiple participation. The lab aims to provide institutional and practical support for the formulation of regional, river basin, and national eco-financing policies and for the implementation of crossregional and cross-domain strategic planning.

\subsubsection{Establish an NECA Mechanism and a Policy Application that Guarantees Transformation "From Green to Gold" and Includes Gender Implications}

\section{Draft and issue Guiding Opinions on Accelerating the NECA and its Policy Appli-} cation. In order to ensure the mainstreaming of NECA into the management and decision-making processes of governments at all levels, it is necessary to clearly normalize and standardize NECA and promote the application of NECA in the fields of eco-financing and spatial planning as both short-term and long-term objectives. Refine target indicators and define completion requirements at each stage, and form the guarantee system for a sound NECA and eco-financing policy development, which provides a basis for securing "lucid waters and lush mountains" as invaluable assets.

Establish a working mechanism to promote NECA and its policy application. Secure an organizational guarantee that the State Council should take the lead in establishing a high-level ecological capital working group with the participation of relevant ministries and agencies, such as the National Development and Reform Commission; the Ministry of Finance; the Ministry of Natural Resources; the Ministry of Ecology and Environment; the Ministry of Water Resources; the Ministry of Agriculture; the Ministry of Housing and Urban, Rural Development; the Ministry of Culture and Tourism; the National Forestry and Grass Administration; and the Chinese Academy of Sciences. The working group should designate the 
responsibilities of relevant departments, improve the working mechanism, arrange work tasks associated with the NECA system and its policy application, and provide sufficient funds.

Deploy the key tasks. Summarize the experiences of pilot projects such as development of Ecological Civilization Experimental Areas, accelerate the establishment of NECA technical methods and specifications, and form standardized accounting guidelines. Accelerate the lab-initiative for NECA and policy simulation by clarifying the work tasks and deadlines of different departments and institutions. Strengthen the verification and evaluation of the accounting results to improve the scientificity and applicability of the accounting results in policy formulation and decision-making, including how ecosystem services are realized via gender and vulnerable populations. Design policies for realizing eco-products' value and strengthen the application of NECA results in the field of eco-financing policies. Formalize and improve related policies for eco-product transactions, ecological banks, PES, and ecological funds to promote the transformation of ecological environment governance from cost attributes to value attributes. Start the pilot projects in Ecological Civilization Experimental Areas to establish the projects' evaluation mechanisms by applying NECA in spatial planning and eco-financing fields. Strengthen capacity building to guarantee ecological capital accounting work.

\subsubsection{Promote Eco-Products Pricing and Trading in Stages: Realizing Value Through Transactions}

Eco-products are different from general products in that their production has the dual attributes of natural reproduction and social reproduction. Their value therefore has the dual attributes of market transactions and compensation. The products have incomplete competition and public goods attributes. They feature higher consumption opportunity costs and complicated consumption willingness. To truly turn the "lucid waters and lush mountains" into "invaluable assets," it is necessary to realize the circulation chain of "ecological resources to ecological assets, then to ecological capital and finally to liquid ecological capital" in stages. To do this, the key is establishing an eco-product pricing and trading system.

\subsubsection{Form a "Three-in-One" Pricing Mechanism for Eco-Products and Establish a Benchmark for the Circulation of Eco-Products}

Determine the price of tradable eco-products through the market. The supply value of eco-products can usually be fully reflected through market transactions. The development of green agriculture and green tourism industries will enhance the intrinsic value of eco-products. To explore the "ecological + " model, establish 
ecological+, brand+, and Internet+ mechanisms to improve the output efficiency of eco-products. To strictly manage an eco-products certification mechanism, establish a unified eco-products standard, certification, and labelling system to guide various social capital investments relying on market mechanisms. Provide a large number of differentiated eco-products to meet consumer demands at different levels.

The government takes the lead in enhancing the value of regulating services and supporting KEFZ services. For eco-products with outstanding ecological functions, non-competitive, non-exclusive and public product attributes-such as national parks, nature reserves, ecological conservation areas, water conservation areas, wild forest areas, ecological restoration management areas, etc.- their function and service value have to be reflected through PES and/or government investment. Through the secondary distribution of financial transfer payments, one can mobilize the enthusiasm of eco-product producers; reasonably allocate the rights and interests of eco-product producers, investors, and beneficiaries; and improve the long-term mechanism of differentiated and coordinated development of different main functional areas.

Comprehensive pricing of eco-environmental resources is explored through government-led trading of eco-environmental resources. On the basis of pollutant emission trading and carbon trading pilots, combined with the standardization process of NECA, scientifically determine the types of rights and interests of ecoenvironmental products that could enter the market. Ensure ownership rights by establishing property rights, and promote the appreciation and circulation of ecological property rights. Explore policy innovations such as bidding and auctioning, mortgage loans, green securities, and eco-financing to promote ownership circulation and ecological assets value increase.

\title{
5.9.2.2 Implement Eco-Product Trading Pilots and Explore Eco-Products Trading Mechanisms
}

\begin{abstract}
Based on water rights trading, explore the mechanism for eco-products trading. Promote water rights trading pilots under the premise of total water use control. Through the registration of water resources use rights, water users are given the right to use and gain water resources in accordance with the law. These water rights need to recognize gendered implications, both in terms of whose labour is involved and who receives the benefits. Based on the regulatory operation and supervision of the primary water rights and the water rights transaction platform, use market mechanisms and information technology to promote water rights transactions across river basins, regions, industries, and different water users. Through the establishment of water rights systems and water rights transactions, promote the optimal allocation of water resources and efficient use in accordance with market competition and market rules.
\end{abstract}


Carry out ecological capital and eco-products trading pilots. Select and determine pilot areas. Check and ratify the supply of eco-products, such as water conservation, carbon sequestration, and pollution purification, and then determine the quantity, quality, and spatial layout of eco-products. Formulate the principles of the ecological rights of the primary market and the trading rules of the secondary market in the pilots. Study the system of empowerment and consumer payment of ecological assets and eco-products, and formulate transaction processes. Explore to build an ecological assets and eco-products trading platform, and allow ecological assets and eco-products to be exchanged with development rights quotas, such as energy rights, water rights, and pollution rights. Try to develop land development rights and ecological rights transactions in the downstream of the river basin. Establish a diversified, market-based OCB mechanism based on the ecological environment capacity, with the participation of government, enterprises, organizations, and communities.

Establish a trading platform for ecological capital and eco-products. Based on the technical support of the National NECA and Policy Planning Simulation Laboratory, establish a national eco-products trading platform and a unified pricing standard for pollution rights and ecological rights. Start rights transactions in virtual markets to form a unified, open, and competitive ecological capital and eco-product market system to promote ecological, environmental and resource transactions across regions and categories. Improve the guarantee system for ecological capital trading platforms, and build a property rights system for ecological capital that is suitable for market transactions. Form a public trading mechanism with standardized procedures.

\subsubsection{Accelerate a Transaction-Based PES System and Establish a Diversified PES Mechanism}

\section{Increase PES programs for regions with prominent ecological functions but rela-} tive poverty. To continuously improve PES standards, expand the scope of national KEFZ payments transfer and change the direction of investment from ecological protection to a combination of ecological protection and the improvement of local livelihood to improve the vital capacity of ecological protection areas. Strengthen benefits evaluation after PES implementation. Encourage the enthusiasm and proactiveness of ecological protectors, and establish a PES mechanism that is compatible, harmonious, and promoted along with local economic development.

Speed up PES along the river basin. In accordance with the principles of "government procurement, market competition, contract management, and rewards \& punishments," establish a PES mechanism based on "beneficiary purchasing" through "open tendering + price negotiation + agreement signing." Issue guidelines and conduct pilot projects for PES along river basins. Establish PES standards for both upstream and downstream of the river basin from water resources, water environment, and water ecology perspectives. Establish joint meetings for the protection and governance of the river basin by linking districts and counties from upstream and 
downstream together. Set reward and punishment mechanisms for PES in order to form a dynamic and scientific PES mechanism with clear subjects, objects, standards, and with various forms.

Establish a trading mechanism for PES based on OCB. With the objective of increasing the total value of ecosystem services, encourage landowners to voluntarily develop the constructed or unused land into ecological land in accordance with regulations; then it can be served as the transaction subject to trade in a PES market. Drawing on ecosystem provisioning and regulating services aspects, formulate transaction standards based on OCB principals. Issue management measures for supervising ecological land transactions, improve supporting systems for ecological land transactions, and conduct trading trials to promote value realization of ecological capitals.

\subsubsection{Carry Out PES Pilot Projects and Trading in the Yangtze River Basin and Strengthen Biodiversity Protection}

Develop PES practices based on water flow regulation services. Provide an accounting of ecological service values such as water regulation, conservation of soil and water and biodiversity conservation in the upstream of the Yangtze River Basin. Based on the accounting results, determine the PES standards between downstream and upstream of the Yangtze River Basin, and promote the implementation of a PES mechanism based on water resource supply and water quality. Increase PES for KEFZ in the upstream of the Yangtze River, and rationally determine the proportion of central fiscal transfer and local payments in the midstream and downstream. Strengthen the promotion and dissemination of PES experiences from the Xin'an River, the Chishui River and rivers across Chongqing, to formulate the Measures for Reward and Punishment on Ecological Quality of Cross-Border Sections of the Yangtze River Basin, and PES Management. Establish a reward and punishment mechanism for mobilizing the proactiveness of PES, and improve the joint alliance of local governments from both upstream and downstream to co-govern the river basins. Unified monitoring and supervision mechanisms will build a long-term mechanism for river basin protection to ensure continuous improvement and the stability of water environment quality.

\section{Explore the establishment of a "forest coupon" trading centre based on an OCB} mechanism. In accordance with the basic principles of "total control, quota management, land conservation, reasonable land supply, and balance between occupation and replenishment," draw on Chongqing's experience through National Bureau of Statistics and manage industrial and mining wasteland in the Yangtze River basin to effectively replenish the amount of forest land to ensure a dynamic and balanced growth of forest land resources along the Yangtze River basin. Set the Yangtze River 
basin's forestry red line to increase year by year, and establish a Yangtze River basin forest coupon transaction centre. Incentivize PES between occupied forest land and newly added forest land to ensure a steady increase in terms of volume and area of forest land.

Increase the protection of and investment in biodiversity in the Yangtze River basin. With the construction of a large number of reservoirs and economic development, a large number of rare and endemic fish-specific spawning grounds and habitats in the upstream of the Yangtze River no longer exist; as a result, the flowing water habitat suitable for spawning of some fish will disappear. Innovate existing regulations on local ecological and environmental damage compensation funds, and promote a joint fund from 11 provinces and cities along the Yangtze River to protect biodiversity and carry out eco-financing policy innovations by initiating the Yangtze River Delta integrated eco-environment protection fund and habitat bank as pilots. Establish a Yangtze River basin projects inventory for ecological protection and eco-financing that includes projects related forestry cultivation, wetland protection, ecological resettlement, etc. Guide various institutional investors to invest in green financial products.

\subsubsection{Strengthen the Application of NECA in Spatial Planning: Optimize Value Through Planning}

China's planning system has long faced problems of systematic incompatibility, content conflicts, inadequate coordination, and a lack of comprehensive evaluation of ecological capital changes and economic and social benefits caused by land-use changes. China is currently carrying out the pilot and reform work of "multi-planning integration," with spatial planning as the core. This will provide an opportunity for ecological capital value to be incorporated into planning decisions, as well as establishing a planning method system based on the integrated considerations of ecological capital and economic benefits and improving the evaluation mechanism of spatial planning. Through scientific planning, the lucid waters and lush mountains will be transformed into invaluable assets to make China a contributor and leader in the construction of the global ecological civilization. 


\title{
5.9.3.1 Include Natural Ecology in the Management of Compulsory Indicators and Strengthen the Role of Spatial Planning in Optimizing and Allocating Natural Ecology
}

\begin{abstract}
Strengthen the binding forces of natural and ecology indicators in planning. Quantitative and qualitative indicators of the five important ecosystem typesforests, grasslands, wetlands, arable land, and oceans - are clearly defined as mandatory indicators and included in the target indicator system for spatial planning. With the overall goal of ensuring that the value of ecological capital does not decrease, propose key planning tasks from multiple aspects, such as establishing an economic and ecological win-win situation, maintaining the ecological capital stock, providing a reasonable flow of ecological capital, strengthening ecological environment construction, and preventing and controlling environmental pollution. Coordinate land and space layout, economic and industrial layout, and urban infrastructure layout through reasonable index settings.
\end{abstract}

Enhance coordinating analysis between natural ecosystems and economic development. Encourage regions where conducting NECA to incorporate indicators of conversion efficiency and output intensity between ecological capital and production capital into the index system. Carry out land resources and environmental capacity evaluation as well as land-use suitability evaluation to promote the continuous adaptation and coordination of the three industrial economies and ecological environment and social development.

Promote a post-evaluation and guarantee system. On the basis of the existing Natural Assets Balance Matrix System, establish an ecological capital assessment system and a dynamic evaluation system of "planning, preparation, implementation, evaluation and plan revision." Coordinate the nationwide results of surveys and evaluations of water, forests, grasslands, wetlands, farmland, and marine minerals to form a unified standard database for spatial planning. In parallel with the preparation of planning, develop a "one-map" supervision information system that comprehensively adopts Big Data, remote sensing, and network informing means to carry out the dynamic monitoring of the planning implementation, and strengthen the supervision of the planning.

\subsubsection{Carry Out Spatial Planning Based on NECA to Improve the Scientificity and Rationality of Spatial Planning}

Establish a technical standard for spatial planning based on NECA. Create a differentiated spatial planning target index system based on the balanced growth of ecological capital and socioeconomics. Through the realization of the value quantification of ecological capital, a spatial planning method system that consists of 
scenario cost-effectiveness analysis, input-output analysis, and econometric analysis will comprehensively improve the scientific rationality of planning strategic decisions.

Promote cost-benefit/effectiveness analysis for both the project and planning levels. Build a framework system for ecological capital and socioeconomic impact assessment for spatial planning with specific assessment methods for different types of planning. Propose an ecological capital and socioeconomic impact assessment index system and methods throughout the entire planning and implementation life cycle. Focus on cost-benefit and/or cost-effectiveness evaluation methods of spatial planning and project implementation. Define assessment frameworks for different types of tasks and projects. Compile a Technical Guide for Cost-Effective Evaluation of Spatial Planning to regulate evaluation indicators, evaluation methods, technical parameters, value parameters, and the application of results. Ensure the accuracy of ecological capital assessment results and provide methodological guidance for funding needs analysis and the project prioritization of ecological protection projects.

Strengthen risk assessment for spatial planning. Establish a risk assessment system for spatial planning from perspectives on population and industry layout, ecological capacity, biodiversity change, and early-warning risk response for the eco-environment. From the perspective of global climate change, major natural disasters, major security events, major environmental events, and extreme events such as major public health events, assess the scientificity, rationality, and effectiveness of spatial planning in terms of protecting public health, maintaining biodiversity stability, and safeguarding national ecological security. Steadily achieve urban-rural spatial planning in all factors with overall coverage and full implementation.

\subsubsection{Insist on "All Ecological Elements" Management and Handle Global Environmental Issues Effectively}

Achieve socioeconomic and eco-environmental "win-win" via spatial planning. Government departments at all levels must adhere to the principle concept of a win-win situation for ecological protection and socioeconomic development when preparing and implementing spatial planning, taking spatial planning as the basis for implementing various development, protection, and construction activities. Fully figure out the bases of various ecological environment factors in the region, and comprehensively evaluate the ecological environment impacts of implementing planned tasks. Promote high-quality economic development and high-level protection of the ecological environment.

Coordinate regional development and ecological balance via spatial planning. Adhere to the thinking of ecological environment as bottom line, carry out NECA, break the administrative regional boundaries of spatial planning, coordinate regional ecological protection and economic development, and ensure the synchronization of 
regional development. Adhere to the horizontal linkage of planning and implementation; break boundaries between upstream and downstream of the river, land, and ocean; promote the restoration and protection of landscapes, forests, lakes, grasses, and marine ecosystems; and maintain the integrity of the ecosystem.

Promote solutions on global environmental issue via spatial planning. Uphold the basic strategy of harmonious coexistence between man and nature, and comprehensively consider the relationship between economic development and global environmental issues, such as biodiversity conservation and climate change. Coordinate environmental governance, ecological protection, and climate change. Through the establishment and improvement of market-based PES and eco-financing policy mechanisms, maintain the healthy and sustainable development of global biodiversity and ecosystems.

\subsubsection{Establish an NECA and Eco-Products Guarantee System for Value Realization: Solidify Value Through Institutional Arrangements}

Strengthen the system design in terms of improving the legal system, the institutional mechanism, and scientific and technological research and development to ensure the innovation and promotion of ecological capital accounting and ecological investment and financing policies. Explore the establishment of a system for determining the property rights of natural resource assets and a trading system for ecological products to improve the spatial planning and ecological compensation system. Through fore-running demonstration and international cooperation, further promote the implementation of ecological product value pilots, fulfill the concept of ecological civilization development proposed by President Xi Jinping, meet the growing needs of the people for satisfied ecological environment, and promote the country's high-quality leapfrog development.

\subsubsection{Establish an Ecological Asset System with Explicit Property Rights and Guarantee the Establishment of Ecological Investment and Financing and Trading Systems}

Improve an ecological capital property rights system. With the State's improving natural resource property rights and the establishment of usage regulation system, promote the verification, registration, and certification of the rights of a spectrum of ecological capital, including water flows, trees, mountains, grasslands, barren land, and tidal flats. Clarify the ownership entity of ecological resources, regulate the right to use ecological resource capital, protect the right to receive ecological resource capital income, activate the right to transfer ecological resource capital, 
and rationalize the right to supervise ecological resource capital. Establish a natural ecology capital property rights system with clear ownership, well-defined rights and responsibilities, and effective supervision.

Clarify ecological capital property rights owners. In accordance with the rule of property rights and the different types of ecological resources, initiate the implementation of the split-operation mechanism of rights, including ecological capital ownership, management rights, contracting rights, etc. Appropriately expand the property rights of a range of ecological capital. Clarify the rights, responsibilities, and interests of the subject of property rights in the possession, use, income, and disposal of ecological capital. Strengthen the supervision of the exercise of property rights over natural resources capital.

\subsubsection{Strengthen Regulations and Technical Support, and Promote the Implementation of Planning Policies and Systems Focusing on NECA}

Establish and improve legal systems to support payment for eco-system use. Fix the rights and obligations for relevant stakeholders, trading of eco-products, compensation for and investment in NECA, spatial planning and eco-financing mechanism in the form of laws and regulations to ensure that the goal of maintaining and increasing ecological capital value is included in the design and implementation of any plans and policies.

Accelerate the establishment of a performance evaluation mechanism based on ecological capital. Develop an integrated regional development index that comprehensively considers economic development and the status of ecological assets as an indicator to reflect the extent of ecological civilization at the regional and river basin levels. Establish distinct assessment index systems for different natural backgrounds and socioeconomic development levels, and clarify the assessment mechanism, assessment subject, assessment object, and application method of the assessment results.

Carry out institutional reform for government agencies. Further clarify the responsibilities of relevant departments, such as Development and Reform, Natural Resources, Ecology and Environment, Agriculture and Rural Development, Water Resources, and Urban Development, in the management of ecological capital. Establish a decision-making mechanism that harmonizes ecological capital, ecological environment quality, and socioeconomic development.

Establish key R\&D projects to improve fundamental capacity building. Implement the key R\&D plan for the realization of ecological capital value and ecofinancing innovation. Develop an ecological resource monitoring network. Start the R\&D of NECA and the policy planning simulation lab. Carry out research on an ecological capital value realization road map and analysis on eco-financing to solve 
technical bottlenecks in terms of tool platforms, technical methods, market mechanisms, institutional policies, and assessment systems that constrain the application of ecological capital in the field of planning and policy.

\subsubsection{Strengthening International Cooperation and Capacity Building, Lay a Solid Foundation}

Strengthen dissemination and training. Carry out basic theoretical training on NECA, spatial planning, and eco-financing policies. Enhance the promotion and interpretation of the practical experiences in Quzhou of Zhengjiang, Wuyishan of Fujian, and Gui'an District of Guizhou. Improve the working capacity of local authorities.

Implement pilot and demonstration works. Set up policy mechanism innovation pilots in the YREB and the Yellow River basin for NECA, spatial planning, eco-products trading, and market-based PES. Innovate a road map on ecological value realization and transformation, and summarize experiences to form practical advantages.

Enhance global cooperation. Carry out international cooperation on NECA tool development, market cultivation of eco-products, strategic development planning for ecological capital, and eco-financing policy innovation.

\subsubsection{Design Eco-Financing Policies for Yellow River Basin: Preserve and Increase Value Through Investment}

At present, the market value realization and distribution mechanism of ecological capital has not been established. The integration of NECA results into traditional financial investment systems is facing technical and institutional obstacles. Eco-financing projects lack a set of scientific and applicable evaluation indicators, evaluation standards, and evaluation methods. The Yellow River is an important ecological barrier and an important economic zone in northern China. The ecological security of the Yellow River basin is related to the prosperity of the country and the nation's revival. Broaden the application of financial instruments in the area of ecological protection of river basins. Promote the interconnection between the ecological asset property market and the traditional financial market. Through the piloting of ecological investment and financing policies in the YREB and the Yellow River basin, a number of replicable, scalable, and applicable river basin ecological investment and financing policy models shall be formed to promote a virtuous circle between economic and social development that recognizes the gendered implications, resources, and environment. 


\title{
5.9.5.1 Coordinate the Economic Development and Eco-Environmental Protection of the Yellow River Basin and Secure an Ecological Barrier
}

\begin{abstract}
Accelerate the formulation and implementation of the Yellow River Ecological Protection and High-Quality Development Plan. From the perspective of spatial development strategy, clearly identify the "three zones" (urban zone, agricultural zone, ecological zone) and the "three lines" (red line for ecological protection, red line for permanent farmland, and urban development boundary) of the Yellow River basin, and define the ecological spatial layout, ecological function, and ecological protection goals of the upstream, midstream, and downstream, as well as key tasks for ecological protection and high-quality development of the Yellow River in the short and medium terms.
\end{abstract}

Formulate and implement control measures according to local conditions that incorporate impacts on gender and vulnerable populations. Carry out a background survey on ecological resources in the Yellow River basin. Investigate the industrial development, energy structure, transportation structure, and land-use status. Scientifically assess the ecological damage and the status of environmental pollution. Focus on sorting out ecological degradation, soil erosion, water pollution landscape fragmentation, animal and plant habitat destruction, and other related ecological protection and environmental governance issues. Fully consider the differences of ecological management requirements in the upstream, midstream, and downstream and estuaries of the Yellow River. Implement comprehensive protection and restoration management in stages and regions.

Gradually build institutional mechanisms that promote the integration of protection and development. Improve the river basin management system, establish and improve a cross-regional management coordination mechanism, and develop a decision-making mechanism based on "government guidance, market leadership, and social participation." Use incentive instruments such as an environmental tax, environmental liability insurance, green credit, green bonds, and eco-product trading means to take comparative advantage of the river basin. Promote the rational flow of various factors for securing high-quality development of urban agglomeration regions along the Yellow River basin.

\subsubsection{Promote Successful Experiences in the YREB for Coordinating the Development of the Upstream, Midstream, and Downstream of the Yellow River}

Explore key role of NECA in eco-financing policies for river basins. Establish the project's economic evaluation system, including the evaluation of ecological capital. Conduct a monetized economic analysis on the eco-environmental impact of investment projects. Fully consider the potential impact on the eco-environment 
during economic development and planning decision-making process. Consider putting potential eco-environment costs, benefits, risks, and returns into investment and financing decisions. Promote economic, ecological, and social sustainable development through the guidance of economic resources.

Explore the ecological capital value formation mechanism. Establish an evaluation method for ecological asset value accounting, and scientifically evaluate the potential value of various types of ecological assets. Strengthen the eco-environment protection payment transfer to areas or river basin that experience poverty but are rich with ecological function, taking into account how those payments have differential impacts based on gender. Explore the establishment of a financial transfer payment mechanism based on the quality and value of ecological assets to determine the PES quota. Improve the trading mechanism of ecological assets in the river basin and promote the linking of initial quotas for energy use rights, carbon emission rights, and pollution rights with ecological asset value accounting.

Expand financing channels. Establish a set of green project identification and evaluation standards, build a project inventory for ecological protection and green development in the Yellow River basin, and evaluate the effectiveness of green projects. Encourage, guide, and attract public-private partnership projects to participate in watershed ecological protection and green development. Encourage financial institutions to carry out green crediting, such as forestry rights loans, public ecological welfare forestry rights pledge loans, and pollution rights loans. Eligible local corporate banks and enterprises are encouraged to deeply connect with the green bond market by issuing green finance bonds and green corporate bonds. Explore the establishment of a river basin green development fund to guide social capital to increase investment in green industries and promote the development of energy conservation and low-carbon industries.

\subsubsection{Innovate the Eco-Financing Policy of the Yellow River Basin, and Alleviate Poverty Through Value-Added from Ecological Capital}

Establish an inventory of ecological assets and NECA in the Yellow River basin. Organize nine provinces and regions along the Yellow River Basin to carry out Natural Ecological Assets Inventory and NECA according to ecosystem elements. Find out the stock and flow of ecological assets. Consider the differences between the ecological background and the economic level of the upstream, midstream, and downstream of the Yellow River basin, trading ecological assets and eco-products in the river basin, determining initial quotas and integrated the pricing of ecological assets and eco-products, and innovating eco-financing policies to provide technical support.

Protect KEFZ in the upstream of the Yellow River and improve the design of PES policies. Focusing on Sanjiangyuan, Qilian Mountains, and south of Gansu, etc., 
as water conservation areas of the upstream Yellow River, establish special funds for ecological protection, restoration, and construction. Draw on the Xin'an River's PES experience to comprehensively consider the water amount and water quality as well as the changes in ecological assets and liabilities to enlarge PES for KEFZ in the upstream of the Yellow River.

\section{Build a green financing reform and innovation pilot area in Gansu's Lanzhou} New District in the midstream of the Yellow River basin and establish an ecofinancing market. Explore the establishment of an eco-financing centre in the Yellow River basin. Develop ecological banks, ecological capital trusts, ecological assets, eco-product trading platforms, and third-party payment pilots to use ecological financial means to support projects such as soil and water conservation, ecological restoration, and biodiversity protection in the river basin to promote the preservation and value-added of ecological capital. Explore the mechanism of cross-regional, eco-environmental damage compensation and PES. Establish an eco-environmental damage compensation fund and a high environmental risk projects' trust fund for off-site transactions to achieve comprehensive eco-environmental governance and protection across regions.

Develop diversified blue financial products downstream. In response to the development and protection of the Yellow River Delta wetlands, innovatively introduce green credit means, such as mortgages for the use of near-ocean areas, mortgages for the use of beaches, and loans for supporting waste circulation. Focus on the finance development of the marine industrial chain. Develop regional industrial clusters, a business district, and a supply chain to create a sustainable "blue finance" service model. Promote the ecosystem health of the Yellow River, and provide fund and policy guarantees for high-quality development in the Yellow River basin.

\section{References}

1. Krutilla. Conservation Reconsidered. Environmental Resources and Applied welfare Economics: Essays in Honor of John V. Krutilla [M]. Washington DC: Resources for the Future: 1988: 10.

2. Costanza R, D'arge R, De Groot R, et al. The value of the world's ecosystem services and natural capital [J]. Nature, 1997,387:253-260.

3. Li W, Zhang B, Xie G. Research on Ecosystem Services in China: Progress and Perspectives [J]. Journal of natural resources, 2009, 24(1): 1-10.

4. Ouyang Z Y, Zheng H, Yue P. Establishment of ecological compensation mechanisms in China: perspectives and strategies [J]. Acta Ecologica Sinica, 2013, 33(3): 0686-0692.

5. Ouyang Z, Zhu C, Yang G, et al. Gross ecosystem product: concept, accounting framework and case study. Acta Ecologica Sinica, 2013, 33 (21): 6747-6761.

6. Xie G, Zhang C, Zhang L, et al. Improvement of the Evaluation Method for Ecosystem Service Value Based on Per Unit Area [J]. Journal of natural resources, 30(8). 1243-1254.

7. Zhu X. The system reform of investment and finance on the Chinese ecosystem environment construction [J]. Social Sciences in Ningxia, 2006, 135(02): 31-38. 
8. The People's Bank of China, Ministry of Finance of the People's Republic of China, National Development and Reform Commission, et al. Guidance on building a green financial system [R/OL].

9. Easterly, William. 2001. "Think Again: Debt Relief", Foreign Policy, November/December: 20-26.

10. Esmon, M. J. and Uphoff, N. T., 1984. "Local Organizations: Intermediaries in Rural Development". Oornell University Press.

11. Shin, Myoung-Ho., 2001, "Financing Development Projects:Public-Private Partnerships". Paper read at OECD/DAC Tidewater Meeting in Penha Longa, Portugal.

12. Chen $\mathrm{P}, \mathrm{Lu} \mathrm{Y}$, Chen $\mathrm{H}$, et al. Study on the Investment and Financing Channels for Environmental Protection [J]. Ecological Economy, 2015, 31(07): 148-151.

13. Wang J, Ge C, Yang J. Environmental Financing Strategy [M]. China Environmental Science Press, 2003.

14. Subhrenduk, Pattanayak. Valuing watershed services: concepts and empirics from Southeast Asia [J]. Agricultural, Ecosystems \& Environment, 2004, 18(12):171-184.

15. Zhang, M., J. Zhou, and R. Zhou. 2018. Interval Multi-Attribute Decision of Watershed Ecological Compensation Schemes Based on Projection Pursuit Cluster. Water 10:1-12.

16. Wang, X., S. Peng, H. Ling, H. Xu, and T. Ma. 2019. Do Ecosystem Service Value Increase and Environmental Quality Improve due to Large-Scale Ecological Water Conveyance in an Arid Region of China? Sustainability 11.

17. Zhao, X., Y. He, C. Yu, D. Xu, and W. Zou. 2019. Assessment of Ecosystem Services Value in a National Park Pilot. Sustainability 11.

18. Aneseyee, A. B., T. Soromessa, and E. Elias. 2019. The effect of land use/land cover changes on ecosystem services valuation of Winike watershed, Omo Gibe basin, Ethiopia. Human and Ecological Risk Assessment.

19. Jiang, Z., X. Sun, F. Liu, R. Shan, and W. Zhang. 2019b. Spatio-temporal variation of land use and ecosystem service values and their impact factors in an urbanized agricultural basin since the reform and opening of China. Environmental Monitoring and Assessment 191.

20. Solomon, N., A. C. Segnon, and E. Birhane. 2019. Ecosystem Service Values Changes in Response to Land-Use/Land-Cover Dynamics in Dry Afromontane Forest in Northern Ethiopia. International Journal of Environmental Research and Public Health 16.

21. Wang, Y., and J. Pan. 2019. Building ecological security patterns based on ecosystem services value reconstruction in an arid inland basin: A case study in Ganzhou District, NW China. Journal of Cleaner Production 241.

22. Gao, X., J. Shen, W. He, F. Sun, Z. Zhang, X. Zhang, C. Zhang, Y. Kong, M. An, L. Yuan, and X. Xu. 2019b. Changes in Ecosystem Services Value and Establishment of Watershed Ecological Compensation Standards. International Journal of Environmental Research and Public Health 16:1-30.

23. Yan, D., Y. Fu, B. Liu, and J. Sha. 2018. Theoretical Study of Watershed Eco-Compensation Standards. Pages 1-6 in K. Wang, editor. 5th Annual International Conference on Material Science and Environmental Engineering.

24. Stephen P, Erik N, Pennington, et al. The Impact of Land Use Change on Ecosystem Services, Biodiversity and Returns to Landowners: A Case Study in the State of Minnesota [J]. Environmental and Resource Economics , 2011, 48(2): 219-242.

25. Erik N, Guillermo M, James R, et al. Modeling multiple ecosystem services, biodiversity conservation, commodity production, and tradeoffs at landscape scales [J]. Frontiers in Ecology and Environment, 2009, 7(1):4-11.

26. Zheng $\mathrm{H}$, Wang L, Peng W, et al. Realizing the values of natural capital for inclusive, sustainable development: Informing China's new ecological development strategy [J]. PNAS, 2019, 116 (17): 8623-8628.

27. Chaudhary, S. et al. "Environmental justice and ecosystem services: A disaggregated analysis of community access to forest benefits in Nepal.” Ecosystem Services. Vol. 29. 2018.

28. Andeltová, L. et al. "Gender aspects in action- and outcome-based payments for ecosystem services-A tree planting field trial in Kenya." Ecosystem Services. Vol. 35. 2019. 
29. Benjamin, E. et al. "Does an agroforestry scheme with payment for ecosystem services (PES) economically empower women in sub-Saharan Africa?" Ecosystem Services. Vol. 31. 2018.

30. Pereira Lima, F. and R. Pereira Bastos. "Perceiving the invisible: Formal education affects the perception of ecosystem services provided by native areas." Ecosystem Services. Vol. 40. 2019.

31. Cruz-Garcia, G. et al. "He says, she says: Ecosystem services and gender among indigenous communities in the Colombian Amazon." Ecosystem Services. Vol. 37. 2019.

32. Pearson, J. et al. "Gender-specific perspectives of mangrove ecosystem services: Case study from Bua Province, Fiji Islands.” Ecosystem Services. Vol. 38. 2019.

33. Defra (2018), A Green Future: Our 25 Year Plan to Improve the Environment. https://www. gov.uk/government/publications/25-year-environment-plan.

34. Millennium Ecosystem Assessment. Ecosystems and human wellbeing: synthesis [M]. Washington DC: Island Press, 2005.

35. TEEB ( edited by Kumar P) . The economics of ecosystems and biodiversity: ecological and economic foundations[M]. London: Earthscan Ltd. 2010.

36. National Forestry and Grassland Administration. LY/T 2006-2012 Assessment criteria of desert ecosystem services in China[S]. Beijing: Standards Press of China, 2012.

37. National Forestry and Grassland Administration. LYT 1721-2008 Specifications for assessment of forest ecosystem services in China [S]. Beijing: Standards Press of China, 2008.

Open Access This chapter is licensed under the terms of the Creative Commons AttributionNonCommercial-NoDerivatives 4.0 International License (http://creativecommons.org/licenses/bync-nd/4.0/), which permits any noncommercial use, sharing, distribution and reproduction in any medium or format, as long as you give appropriate credit to the original author(s) and the source, provide a link to the Creative Commons license and indicate if you modified the licensed material. You do not have permission under this license to share adapted material derived from this chapter or parts of it.

The images or other third party material in this chapter are included in the chapter's Creative Commons license, unless indicated otherwise in a credit line to the material. If material is not included in the chapter's Creative Commons license and your intended use is not permitted by statutory regulation or exceeds the permitted use, you will need to obtain permission directly from the copyright holder.

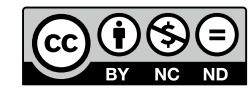

